\title{
Inner Canthal Distance, Inter Pupillary Width, and Golden Proportion, as Predictors of Width of the Maxillary Central Incisors - An In Vivo Study
}

\author{
Sanath Kumar Shetty ${ }^{1}$, Prakyath Malli2, Joana D' Souza ${ }^{3}$, \\ Kamalakanth Shenoy ${ }^{4}$, Surya Teja Chunduri ${ }^{5}$, Kevin Fernandes ${ }^{6}$ \\ 1, 2, 3, 4, 5, 6 Department of Prosthodontics Including Crown \& Bridge, \\ Yenepoya Dental College, Deralakatte, Mangalore, Karnataka, India.
}

\section{ABSTRACT}

\section{BACKGROUND}

The mesio-distal width of anterior teeth can be determined by certain anthropometric measurements of face. The inter pupillary width is a facial landmark that is stable and does not modify after the age of 14 years. This study intended to determine if any relationship exists between inner canthal distances (ICD), inter-pupillary width (IPW), and golden proportion in determining the association between them and the maxillary central incisor width (CIW).

\section{METHODS}

252 adult dentate subjects of age group 18 - 26 years who were free from dentofacial deformities were evaluated in the present in vivo study. The mesiodistal measurement of each maxillary central incisor, inner canthal distance (ICD), interpupillary width (IPW) was measured. The inner canthal distance of each subject was multiplied by a decreasing function of the geometric progression value (0.618) to provide the total width of two central incisors. The product was divided by 2 to get the width of a maxillary central incisor. A ' $t$ ' test was used to establish significant differences if any in the mesiodistal width of the maxillary central incisors (CIW), inner canthal distance (ICD), and inter-pupillary width (IPW). Concurrence between the measured and calculated central incisor widths was evaluated using Pearson's correlation coefficients.

\section{RESULTS}

The mean ICD of male and female subjects was $33.03 \pm 3.037 \mathrm{~mm}$ and $30.75 \pm 2.89$ $\mathrm{mm}$, respectively. The mean IPW of male and female subjects was $62.26 \pm 2.99 \mathrm{~mm}$ and $58.46 \pm 2.73 \mathrm{~mm}$, respectively. The mean CIW of male and female subjects was $19.98 \pm 1.96 \mathrm{~mm}$ and $18.54 \pm 1.87 \mathrm{~mm}$, respectively. A high correlation was found between the measured and calculated width of central incisors $(r=0.954$ and $r=0.974$ in males and females).

\section{CONCLUSIONS}

There is a high positive correlation between ICD and CIW and it exists in the golden proportion. On the other hand, it was seen that the IPW and CIW were not in golden proportion. The mean of calculated CIW was significantly higher compared to the measured CIW in both males and females. ICD was seen as a significant factor in determining the CIW in males and females. All the facial and dental measurements were greater for men than for women; however, no significant differences were found between sexes with respect to ICD.

\section{KEY WORDS}

Inner Canthal Distance (ICD), Inter Pupillary Width (IPW), Central Incisor Width (CIW), Golden Proportion
Corresponding Author: Dr. Prakyath Malli, Department of Prosthodontics Including Crown \& Bridge, Yenepoya Dental College,Deralakatte, Mangalore, Karnataka, India.

E-mail: prakyathm14@gmail.com

\section{DOI: $10.14260 / \mathrm{jemds} / 2021 / 343$}

How to Cite This Article:

Shetty SK,Malli P, D' Souza J et al. Inner canthal distance, inter pupillary width, and golden proportion, as predictors of width of the maxillary central incisors - an in vivo study. J Evolution Med Dent Sci 2021;10(22):1650-1655, 10.14260/jemds/2021/343

Submission 10-01-2021, Peer Review 31-03-2021, Acceptance 05-04-2021, Published 31-05-2021.

Copyright (c) 2021 Sanath Kumar Shetty et al. This is an open access article distributed under Creative Commons Attribution License [Attribution 4.0 International (CC BY 4.0)] 


\section{BACKGROUND}

The oral cavity is of significant importance to one's social image. The teeth constitute one of the important structures in this complex which enhances the aesthetic value of the person. The majority of individuals seek dental care following the loss of teeth due to functional and aesthetic reasons. Maxillary central incisors play a substantial role in devoting to the pleasing appearance of an individual. Aesthetics is one of the important aspects of complete denture fabrication.1-7 and when the pre-extraction records are not obtained, it is exceedingly laborious to select teeth to bring out the harmony with facial appearance. ${ }^{8-11}$ The tooth size and facial appearance must be harmonious. To appear aesthetically acceptable, maxillary anterior teeth must be in proper ratio or proportion to facial morphology. Ratio or proportion is the study of the allegiance of structures in space. The golden proportion has been in use for many generations. It has been well illustrated in Greek architecture E.g.: Acropolis and Leonardo da Vinci used the golden proportion in their drawings. Because of their monumental importance in geometry and architecture and their demonstration in nature, these ratios are called golden proportions. ${ }^{12-14}$

Levin ${ }^{15}$ used the golden proportion to relate the ensuing widths of the anterior teeth and stated that "width of the central incisor should be in golden proportion to the width of the lateral incisor and that the width of the lateral incisor to the width of the canine". Lombardi stated that when this repeated ratio is equal to the golden mean, the composition is said to be esthetic. ${ }^{16}$ Studies were conducted and anthropometric evaluations of the face have been utilized as a guide in determining appropriately sized anterior teeth which include bizygomatic width, inter commissural width, inter pupillary width, inter alar width, and inner canthal distance. ${ }^{17,18}$ The inner canthal distance (ICD) of 28 to $35 \mathrm{~mm}$ is considered to be normal irrespective of sex, race, and age. ${ }^{19}$ Thus, this distance is a reliable anatomic value that will give a credible approach to anterior teeth selection. A study, ${ }^{19}$ showed a high positive correlation between inner canthal distance and central incisors width, combined incisor widths, and the combined width of anterior teeth. The inter-pupillary width is the distance measured from the mid-pupil of one eye to mid-pupil of the other eye. Only inter-pupillary distance probably remains constant irrespective of age changes. ${ }^{20}$

Although, Colossal of efforts have been put in the past by numerous clinicians to gauge the relationship between various landmarks of the face with the width of central incisors, ${ }^{21-24}$ the results are contradictory. As there is lack of clarity in literature, a study has to be done to see if the various landmarks of face such as inner canthal distance, the inter-pupillary width, and the golden proportion were helpful in determining the maxillary central incisors width.

\section{METHODS}

The present in vivo study was conducted for a duration of 24 months from $2^{\text {nd }}$ February 2014 to $1^{\text {st }}$ February 2016 in the Department of Prosthodontics, Crown and Bridge, Yenepoya Dental College, Mangalore, Karnataka, India. A total of 252 adult dentate subjects were selected among the students of
Yenepoya Deemed to be University forth is study. All subjects examined were between the age group of 18 - 26 years. The 252 subjects were equally divided into males and females' group. The criteria for selection of subjects was the presence of full complements of periodontally healthy and caries-free teeth. All subjects with the history of orthodontic treatment, pathological migration, traumatic occlusion of anterior teeth, and or any periodontal disease, extractions, deflective occlusal contacts, spacing or crowding, attrition of maxillary anterior teeth were excluded.

Ethical clearance with protocol number 2013 / 162 was obtained from the ethics committee of the university and informed consent was obtained from the study subjects. For measuring the maxillary central incisor width (CIW), subjects were made to sit on a dental chair, heads supported in an upright position. A digital vernier caliper (Aerospace, china) (Figure1) was placed such that the beaks of the instrument were at the widest dimension of the maxillary central incisors. The value on the digital vernier caliper was then recorded (Figure 2). The impression of the maxilla was made with alginate (Tropicalgin, Zhermack, Italy) and the cast was poured using type III dental stone (Ramraju surgical cotton mills, India) (Figure3). The combined mesiodistal width of the maxillary incisors was measured again at the widest dimension on the cast obtained and the measurement was recorded in millimetres.

For measuring inner canthal distance, subjects were made to sit on a dental chair, heads supported in an upright position so that they look forward. A digital vernier caliper was placed against their forehead and then lowered towards their eyes. The median angle of the palpebral fissures of both eyes were made to come in contact with the arms of the digital vernier caliper (Figure 4). ICD was recorded as the distance between two anatomical landmarks. The measured distance was compared with the combined width of maxillary incisors in each subject and a correlation between the inner canthal distance and the golden proportion was obtained. The inter pupillary width was measured by asking the patient to sit upright. Mid pupil region of eye was made to be in line with the arms of the caliper, the value obtained on digital vernier caliper was recorded as the distance between two anatomical landmarks. The value on the digital vernier caliper was then recorded (Figure 5). The measured IPW was compared to the central incisor width.

\section{Statistical Analysis}

The data were entered into statistical software (SPSS version 11) and analysed applying independent sample t test, it was used to establish any significant differences in the CIW, ICD, and IPW. Shapiro-Wilk test was used to assess the normality and paired sample t test was used for comparing measured and calculated CIW and Pearson's correlation was used for comparison. $\mathrm{P}$ value less than 0.05 was considered as significant.

\section{RESULTS}

Table 1 shows the observations and statistical calculations done using independent sample $t$ test and shows the mean 
CIW to ICD ratio, CIW to IPW ratio, ICD, CIW, and age compared between male and female subjects.

Table 1 shows that the mean ratio of CIW to ICD in males was $0.605 \pm 0.018$ and in females, it was $0.603 \pm 0.014$, the difference is statistically not significant $(\mathrm{P}=0.276)$. Both in males and females, the ration was very close to the golden proportion of 0.618 and was analysed that the ICD and CIW are in golden proportion. It was also inferred that the mean ratio of CIW to IPW in males was $0.322 \pm 0.0335$ and in females, it was $0.317 \pm 0.0273$, the difference is statistically not significant. Both in males and females, the ratio was not coinciding with the golden proportion of 0.618 and was analysed that the IPW and CIW are not in golden proportion. From Table 1 , the mean ICD value in males $(33.03 \pm 3.037$ $\mathrm{mm}$ ) was significantly higher ( $\mathrm{P}$ value $=0.001$ ) compared to mean ICD of females $(30.75 \pm 2.89 \mathrm{~mm})$. Here, it was observed that there was a gender-based difference in ICD (males: $33.03 \pm 3.037 \mathrm{~mm}$; females: $30.75 \pm 2.89 \mathrm{~mm}$ ). The mean IPW value in males $(62.26 \pm 2.99 \mathrm{~mm})$ was significantly higher $(\mathrm{P}$ value $=0.001)$ compared to mean IPW of females $(58.46 \pm 2.73 \mathrm{~mm})$. There was a significant difference in CIW $(\mathrm{P}$ value $=0.001)$ observed between males $(19.98 \pm 1.96 \mathrm{~mm})$ and females (18.54 $\pm 1.87 \mathrm{~mm}$ ). Also, no significant difference in age $(\mathrm{P}$ value $=0.053)$ was observed between males $(20.8 \pm$ 2.69 years) and females ( $21.46 \pm 2.68$ years $)$.

Tables 2, 3, 4 and 5 show the measured and calculated maxillary central incisor width in males as well as females. The Shapiro-Wilk test was used to assess the normality of measured and calculated CIW. The normality assumption was verified, and paired t test was used for comparison. Table 2, showed the calculated value of CIW (20.41 $\pm 1.88 \mathrm{~mm})$ was significantly higher compared to measured CIW $(19.98 \pm 1.96$ $\mathrm{mm}$ ) in males $(\mathrm{P}$ value $=0.001)$. Table 3 , shows the Pearson's correlation between measured and calculated CIW in males ( $\mathrm{r}$ $=0.954)$ was significant $(\mathrm{P}$ value $=0.001)$. Table 4 shows the calculated value of CIW $(19.00 \pm 1.78 \mathrm{~mm})$ significantly higher compared to measured CIW $(18.54 \pm 1.87 \mathrm{~mm})$ in females (P value $=0.001)$.Table 5 , shows the Pearson's correlation between measured and calculated CIW in females $(r=0.974)$ was significant(P value $=0.001)$. From the Tables $2,3,4$ and 5 , it was found that, there was a high positive correlation between the measured and calculated values of CIW in males $(r=0.954)$, as well as females there was a correlation between the measured and calculated CIW $(r=0.974)$.

\section{DISCUSSION}

Aesthetics is a prime factor in the present age that determines the outcome of any prosthesis. In situations where the pre-extraction records may be unavailable, the selection of anterior teeth becomes a task. The mesio-distal width of the maxillary central incisor when seen from frontal aspect is considered to be most pivotal as they are more pronounced. The golden proportion is a mathematical term that is incorporated in nature. It describes the ratio between a large and small length. Golden Proportion is $1.618: 1$ and its reciprocal is 0.618 in geometry. The inner canthal distance and interpupillary distance remain constant and do not change after acertainage. ${ }^{25,26 \text { Serving as a reliable }}$ prognosticator of the width of maxillary central incisors. The present study was overseen to find whether there is a correlation between the inner canthal distance (ICD), the interpupillary width (IPW), and the golden proportion in determining the width of the maxillary central incisors (CIW). A total of 252 subjects among the age group of $18-26$ were assessed. The subjects covered were the students of Yenepoya Deemed to be University, who were free from any malocclusion or restoration. A total of 252 subjects were sub classified into males and female group with each consisting of 126 subjects. A digital vernier caliper was used to determine the distance between the inner-canthus, inter-pupillary, and maxillary central incisors, by placing it contrary to the patient's face.

Previous investigators have focused on estimating the mesio-distal width of maxillary central incisors with the aid of inner canthal distance and golden proportion. Abdullah M.A. ${ }^{11}$ reported a higher mean maxillary central incisor width and inner canthal distance. It was recorded that the mean CIW recorded $(8.7 \mathrm{~mm})$ compared favourably with that reported by Cesario et al. ${ }^{20}(8.90 \mathrm{~mm})$. When the subjects were segregated based on gender, a higher mean CIW was found for males than for females. He concluded that the ICD may be a safe predictor of the width of the maxillary central incisor. In a study conducted by George S. et al. ${ }^{7}$ it was also found that a high positive correlation between the ICD and CIW was in golden proportion. In a study by Wazzan. A. ${ }^{13}$ reported that the mean mesio-distal width of the central incisors in males was higher than females. These findings were congruent with that of the present study where the mean findings of the CIW and ICD were 0.605 in males and 0.603 in females. An observation that the value for males was higher than females. The resultant values also proved that the ICD and CIW were in golden proportion $(0.618)$.

\section{Inner Canthal Distance (ICD)}

The inner canthal distance was selected as a reference guide because it is a stable landmark that has a slow growth rate in contrast to the outer orbital dimensions. At the age of 5, 93\% of ICD growth has been achieved and maturity is reached between $8-11$ years. The ICD of $28 \mathrm{~mm}$ to $35 \mathrm{~mm}$ is considered to be normal irrespective of sex, race, and age. ${ }^{25}$

The subjects were made to sit on the dental chair with the mandible parallel to the floor of mouth and ICD was measured. The median angle of the palpebral fissures of both eyes were made to come in contact with the arms of the digital vernier caliper. ICD was recorded as the distance between two anatomical landmarks.

The ICD showed a median of $31.89 \mathrm{~mm}$. Studies have shown a mean of $28.30 \mathrm{~mm}^{12}$ and $31.92 \mathrm{~mm} .{ }^{19}$ Pearson's correlation test showed a positive correlation between the ICD and the CIW. These findings indicate that the ICD could be used to select maxillary anterior teeth for edentulous patients.

\section{Inter-Pupillary Width (IPW)}

IPW was also measured similarly to the ICD. The arms of the digital vernier Calliper's were adjusted such that they were placed right in the center of the pupils on either side. The distance from the mid pupil to mid pupil was recorded as the IPW. 
It has been seen that the interpupillary distance remains fairly constant once the growth of the individual stops. ${ }^{26-28}$

In a previous study, the mean IPW value was $59.16 \mathrm{~mm}$, after measuring 100 subjects of the US Army. ${ }^{20}$ In the present study, the mean IPW was found to be $62.26 \mathrm{~mm}$ in males and $58.46 \mathrm{~mm}$ in females, males having greater measurements than females. The mean value for all subjects was $60.36 \mathrm{~mm}$ which is in concurrence with the previous study. (Table1)

\begin{tabular}{|c|c|c|c|c|c|}
\hline Variable & Gender & Mean & $\begin{array}{l}\text { Standard } \\
\text { Deviation }\end{array}$ & t-Value & P-Value \\
\hline CIW / ICD & $\begin{array}{c}\text { Male } \\
\text { Female }\end{array}$ & $\begin{array}{l}0.605 \\
0.603\end{array}$ & $\begin{array}{l}0.018 \\
0.014\end{array}$ & 1.091 & 0.276 \\
\hline CIW / IPW & $\begin{array}{l}\text { Male } \\
\text { Female }\end{array}$ & $\begin{array}{l}0.322 \\
0.317\end{array}$ & $\begin{array}{l}0.033 \\
0.027\end{array}$ & 1.172 & 0.242 \\
\hline ICD & $\begin{array}{l}\text { Male } \\
\text { Female }\end{array}$ & $\begin{array}{l}33.03 \mathrm{~mm} \\
30.75 \mathrm{~mm}\end{array}$ & $\begin{array}{c}3.037 \mathrm{~mm} \\
2.89 \mathrm{~mm}\end{array}$ & 6.11 & 0.001 \\
\hline IPW & $\begin{array}{l}\text { Male } \\
\text { Female }\end{array}$ & $\begin{array}{l}62.26 \mathrm{~mm} \\
58.46 \mathrm{~mm}\end{array}$ & $\begin{array}{l}2.99 \mathrm{~mm} \\
2.73 \mathrm{~mm}\end{array}$ & 10.54 & 0.001 \\
\hline CIW & $\begin{array}{l}\text { Male } \\
\text { Female }\end{array}$ & $\begin{array}{l}19.98 \mathrm{~mm} \\
18.54 \mathrm{~mm}\end{array}$ & $\begin{array}{l}1.96 \mathrm{~mm} \\
1.87 \mathrm{~mm}\end{array}$ & 5.98 & 0.001 \\
\hline Age & $\begin{array}{c}\text { Male } \\
\text { Female }\end{array}$ & $\begin{array}{l}20.80 \mathrm{~mm} \\
21.46 \mathrm{~mm}\end{array}$ & $\begin{array}{l}2.69 \mathrm{~mm} \\
2.68 \mathrm{~mm}\end{array}$ & 1.95 & 0.053 \\
\hline
\end{tabular}

\section{Central Incisor Width (CIW)}

The combined width of the maxillary central incisors was measured at their contact points intra-orally with the arms of the digital vernier calliper placed against the widest point of the central incisors. In the present study, the contact area was taken into consideration because the mesio-distal width of the incisors is maximum at their contactpoints. ${ }^{12,19,29-35 T h i s ~}$ measurement was recorded as the CIW.

In the present study, all the tooth dimensions were larger in males than in females. The mean CIW for males being $19.98 \mathrm{~mm}$ and for females being $18.54 \mathrm{~mm}$. This result was in concurrence to previous studies where Gillen et al. and Sterret et al. noted that the maxillary anterior teeth of men were wider and longer than those of women. ${ }^{36-38}$ (Table1)

The present study also showed that the calculated CIW was higher compared to the measured CIW in males $(20.41$ $\mathrm{mm}>19.98 \mathrm{~mm})$ as compared to females $(19.00 \mathrm{~mm}>18.54$ $\mathrm{mm})$. (Table 2-5)

\begin{tabular}{|cccccc|}
\hline Central Incisor Width & n & Mean & Std. Dev. & t-Value P - Value \\
CIW (measured) & 126 & $19.98 \mathrm{~mm}$ & $1.96 \mathrm{~mm}$ & \multirow{2}{*}{8.22} & 0.001 \\
CIW (computed) & 126 & $20.41 \mathrm{~mm}$ & $1.88 \mathrm{~mm}$ & & \\
\hline \multicolumn{5}{c}{ Table 2. Comparison of Measured and } \\
Computed CIW in Males - Paired t-test & \\
\hline
\end{tabular}

\begin{tabular}{|ccccc|}
\hline & & Correlation 'r' & P - Value \\
\hline Male & Measured CIW \& Computed CIW & 126 & 0.954 & 0.001 \\
\hline \multicolumn{4}{|c|}{ Table 3. Pearson's Correlation } \\
\hline
\end{tabular}

\begin{tabular}{|cccccc|}
\hline Central Incisor Width & n & Mean & $\begin{array}{c}\text { Standard } \\
\text { Deviation }\end{array}$ & t - value P - Value \\
CIW (measured) & 126 & $\begin{array}{c}18.54 \\
\mathrm{~mm}\end{array}$ & $1.87 \mathrm{~mm}$ & 12.19 & 0.001 \\
CIW (computed) & 126 & $\begin{array}{c}19.00 \\
\mathrm{~mm}\end{array}$ & $1.78 \mathrm{~mm}$ & & \\
\hline \multicolumn{5}{|c|}{ Table 4. Comparison of Measured and } \\
Computed CIW in Females - Paired t-Test
\end{tabular}

\begin{tabular}{|ccccc|}
\hline & & n & Correlation ' $r$ ' & P - Value \\
\hline Female & Measured CIW \& Computed CIW & 126 & 0.974 & 0.001 \\
\hline \multicolumn{4}{|c|}{ Table 5. Pearson's Correlation } \\
\hline
\end{tabular}

When all the 252 subjects were analyzed together their mean ICD was found to be $31.89 \mathrm{~mm}$. The mean CIW was found to be $19.26 \mathrm{~mm}$ and the mean IPW was found to be $60.36 \mathrm{~mm}$. Scandrett et al. ${ }^{11}$ suggested that more than one anatomic reference is needed to predict the width of maxillary anterior teeth. (Table 1)

The ICD was found to be exceeding than the combined widths of the maxillary central incisors. Hence, the ICD of each subject was multiplied by a decreasing function value of the geometric progression term $(0.618)$ to provide the combined width of two central incisors. The product was then divided by 2 to obtain the width of a single maxillary central incisor. ${ }^{13}$ It was found that there was a high positive correlation between the measured and calculated values of CIW. Since the calculated central incisor width is the product of golden proportion with ICD (ICD*0.618), the measured central incisor width also should be in golden proportion to ICD. That is, ICD and CIW are in golden proportion. ${ }^{12}$

The present study was in concurrence with the study done by Abdullah M.A et al. ${ }^{6}$ as the mean ratio of CIW to ICD in males was 0.605 and in females, it was 0.603 ( $\mathrm{P}$ value $=$ 0.276). (Table1)

\section{Golden Proportion}

The golden proportion is $1.618: 1$ and it's reciprocal 0.618 in geometry. Any decreasing function is multiplied by 0.618 and any increasing function by 1.618 to get the next result.12 Since ethnic differences can exist between populations, universal application of the research work can only be possible when it is applied and studied in different populations. So, further studies regarding these parameters should be carried out to find ways to predict the width of the maxillary central incisors, preserving in mind the aesthetic standpoint. The present study inferred that the inner canthal distance is a reliable guide for the prediction of the width of the maxillary central incisors and was in congruence with the golden proportion. The inter papillary width did not show any significant difference with the maxillary central incisors and could also be adapted as a predictor for the CIW. But, the IPW did not concur with the golden proportion.

The mean CIW to ICD ratio, CIW to IPD ratio, ICD, CIW and age was compared between male and female subjects, applying independent sample t-test. The mean computed value of CIW $(20.41 \mathrm{~mm})$ was significantly higher compared to measured CIW $(19.98 \mathrm{~mm})$ in males ( $\mathrm{P}$ value < 0.05 ) (Table 2). High positive correlation was observed between measured and computed CIW. Pearson's correlation between measured and computed CIW in males ( $\mathrm{r}=0.954)$ was significant $(\mathrm{P}$ value $<0.05)$ (Table 3 ). The mean computed value of CIW $(19.00 \mathrm{~mm})$ was significantly higher compared to measured CIW $(18.54 \mathrm{~mm})$ in females (P value $<0.05)$ (Table 4). High positive correlation was observed between measured and computed CIW. Pearson's correlation between measured and computed CIW in females $(r=0.974)$ was significant (P value < 0.05) (Table 5).

\section{CONCLUSIONS}

Within the limits of the present study and on the basis of the results obtained, it can be concluded that, there is a high positive correlation between ICD and CIW and it exists in the golden proportion. On the other hand, it was seen that the 
IPW and CIW were not in golden proportion. The mean of calculated CIW was significantly higher compared to the measured CIW in both males and females. ICD was seen as a significant factor in determining the CIW in males and females. All the facial and dental measurements were greater for men than for women; however, no significant differences were found between sexes with respect to ICD.

\section{Limitations of the Study}

Standard and uniform protocol in measuring the ICD, IPW, and CIW were carried out. Discrepancy, if any due to human error was unavoidable. Only students of Yenepoya (Deemed to $\mathrm{Be}$ ) University were evaluated and subjects were selected within a narrow age range. It is possible that ethnic related differences in inner canthal distance may exist. The sample size selected is small and may not represent the group completely.

\section{Scope for Further Studies}

The present study utilized three criteria namely, ICD, IPW, and golden proportion to predict a correlation between them and the CIW. A further study will be required to see if these factors along with other anthropometric measurements will be useful for predicting the width of the CIW in geriatric patients.

Data sharing statement provided by the authors is available with the full text of this article at jemds.com.

Financial or other competing interests: None.

Disclosure forms provided by the authors are available with the full text of this article at jemds.com.

\section{REFERENCES}

[1] Bhat VS, Prasad DK, Malli P. Asurveytoassesspatientsatisfactionafterreceivingcomple te denture prostheses in $\mathrm{AB}$ Shetty Memorial Institute of Dental Sciences. Nitte University Journal of Health Science 2014;4(2):81-5.

[2] Ward

DH.Proportionalsmiledesignusingtherecurringestheticde ntal(red)proportion. Dent Clin North Am2001;45(1):143-54.

[3] Hashim HA, Murshid ZA. Mesiodistal tooth width, a comparison between Saudi males and females. Part I. Egypt Dent J 1993;39(1):343-6.

[4] Mavroskousfis F, Ritchie GM. Nasal width and incisive papilla as guides for the selection and arrangement of maxillary anterior teeth. J Prosthet Dent1981;45(6):5927.

[5] Griffin T. More than just in central position. Part II: A form and natural appearance. Dent Pract2003;4:12-4.

[6] Abdullah MA. Inner canthal distance and Geometric progression as a predictor of maxillary central incisor width. J Prosthet Dent 2002;88(1):16-20.

[7] George S, Bhat V. Inner canthal distance and golden proportion as predictors of maxillary central incisor width in south Indian population. Indian J Dent Res2010:21(4):491-5.
[8] Renner RR. AnIntroductiontodentalanatomyandesthetics. $\quad 1^{\text {stedn }}$ Chicago, US: QuintessencePublishingCo. Inc 1985: p. 249.

[9] Bell AR. The geometric theory of selection of artificial teeth: is it valid? J Am Dent Assoc 1978;97(4):637-40.

[10] Behanam M, Padmanabhan TV, SubramanianR. The golden proportion in aesthetic treatment planning. J Indian Prosthodontic Society 2004;4(4):5-8.

[11] Scandrett FR, Kerber PE, Umrigar ZR. A clinical evaluation of techniques to determine thecombinedwidthofthemaxillaryanteriorteethandthema xillarycentralincisor. JProsthet Dent1982;48(1):15-22.

[12] Al-El-Sheikh HM, Al-Athel MS.The relationship of interalar width, interpupillary width and maxillary anterior teeth width in Saudi population. OdontostomatolTrop 1998;21(84):7-10.

[13] Al

WazzanKA.Therelationshipbetweenintercanthaldimensi onandthewidthofmaxillary anterior teeth. J Prosthet Dent 2001;86(6):608-12.

[14] Cesario VA Jr, Latta GH Jr. Relationship between the mesiodistal width of the maxillary central incisor and interpupillary distance. J Prosthet Dent1984;52(5):6413.

[15] Levin EI. Dental aesthetics and the golden proportion. J Prosthet Dent 1978;40(3):244-52.

[16] Sellen PN, Jagger DC, Harrison A. Methods used to select artificial anterior teeth for the edentulous patient: a historical overview. Int J Prosthodont1999;12(1):51-8.

[17] Latta GH Jr, Weaver JR, Conkin JE. The relationship between the widths of the mouth, inter alar width, bizygomatic width and interpupillary distance in edentulous patients. J Prosthet Dent1991;65(2):250-4.

[18] Lavere AM, Marcroft KR, Smith RC, et al. Denture tooth selection: an analysis of the natural maxillary incisor compared to the length and width of the face. Part I. J Prosthet Dent1992;67(5):810-2.

[19] LaestadiusND,AaseJM,SmithDW. Normalinnercanthalandouterorbitaldimensions. J Pediatr 1969;74(3):465-8.

[20] Filipovic T. Changes in the inter pupillary distance (IPD) with ages and its effect on the near convergence/ distance (NC/D) ratio. Coll Antropol 2003;27(2):723-7.

[21] Lucas WP, Pryor HB. Range and standard deviations of certain physical measurements in healthy children. J Pediatr 1935;6(4):533-45.

[22] Bindra B, Basker RM, Besford JN. A study of the use of photographs for denture tooth selection. Int J Prosthodont 2001;14(2):173-7.

[23] BaskerRM,DavenportJC.Prosthetictreatmentoftheedentul ouspatient. $\quad 4^{\text {thedn.Oxford: Blackwell Publishing }}$ Company2002.

[24] AbdullahMA,StiphoHD,TalicYF,et al.Thesignificanceofinnercanthaldistance in prosthodontics. The Saudi Dental Journal 1997;9(1):369.

[25] Gomes VL,Goncalves LC, Do Prado CJ, et al. Correlation between facial measurements and the mesio distal width of the maxillary anterior teeth. J Esthet Restor Dent 2006;18(4):196-205.

[26] Tandale UE, Dange SP, Khaliakr AN. Biometric relationship between inter canthal 
dimensionandthewidthsofmaxillaryanteriorteeth.JIndian ProsthodontSoc2007;7(3):123-5.

[27] Isa ZM, Tawfiq OF, Noor NM, et al. Regression methods to investigate the relationship between facial measurements and widths of maxillary anterior teeth. J Prosthet Dent 2010;103(3):182-8.

[28] Lucas BL, Bernardino-Junior R, Goncalves LC, et al. Distance between the medial anglesoftheeyesasananatomicalparameterfortoothselecti on.JOralRehabil 2009;36(11):840-7.

[29] Knezovic ZD, Kristek E, Celebic A. Analysis of width/length ratios of normal clinical crowns of the maxillary anterior dentition: correlation between dental proportions and facial measurements. Int J Prosthodont 2007;20(3):313-5.

[30] Hasanreisoglu U, Berksun S, Aras K, et al. An analysis of maxillary anterior teeth: facial and dental proportions. J Prosthet Dent 2005;94(6):530-8.

[31] GillenRJ,SchwartzRS,HiltonTJ,et al.Ananalysisofselectednormativetooth proportions. Int J Prosthodont 1994;7(5):410-7.
[32] Sterrett JD, Oliver T, Robinson F, et al. Width/ length ratios of normal clinical crowns of the maxillary anterior dentition in man. J Clin Periodontol 1999;26(3):153-7.

[33] RickettsRM.Thebiologicsignificanceofthedivineproportio nandFibonacciseries.Am J Orthod 1982;81(5):351-70.

[34] Koury ME, Epker BN. Maxillofacial esthetics: anthropometrics of the maxillofacial region. J Oral Maxillofac Surg 1992;50(8):806-20.

[35] LavelleCL.Maxillaryandmandibulartoothsizeindifferentra cialgroupsandindifferent occlusal categories. Am J Orthod 1972;61(1):29-37.

[36] Wu KH, Tsai FJ, Li TC, et al. Normal values of inner canthal distance, inter pupillary distance and palpebral fissure length in normal Chinese children in Taiwan. Acta Paediatr Taiwan 2000;41(1):22-7.

[37] Evereklioglu C, Doganay S, Er H, et al. Craniofacial anthropometry in a Turkish population. Cleft Palate Craniofac J 2007;39(2):208-18.

[38] Osuobeni EP, Al-Ibraheem AM. Occular and facial dimensions of male Arab children. J Am Optom Assoc 1993;64(10):717-22. 